\title{
Cultivating hope for a better future: research contributions from young scholars in earth and environmental sciences
}

\author{
Peiyue Li ${ }^{1,2}$ (1) Ken W. F. Howard ${ }^{3} \cdot$ Matthew Currell $^{4}$
}

Received: 3 April 2017 / Accepted: 10 April 2017 / Published online: 21 April 2017

(C) Springer-Verlag Berlin Heidelberg 2017

\section{Introduction}

With Earth's environment changing rapidly due to global climate change, population growth, and human activities, the future is becoming very difficult to predict. Uncertainty drives scientific curiosity and thirst for knowledge and solutions, but it can also lead to insecurity, anxiety, and fear. Few will dispute that life on earth is becoming increasingly threatened by environmental problems such as air pollution, water contamination, and degradation of soils, issues that can be commonly linked to unregulated human activities and irresponsible policymaking (Currell and Han 2017; Howard and Howard 2016; Li et al. 2014, 2015, 2017a). But, how will these environmental problems affect our future and how can they be resolved? Such questions are clearly very difficult to answer, but where there is will, there is hope, and scientists throughout the world diligently continue

Responsible editor: Philippe Garrigues

Peiyue Li

lipy2@163.com; peiyueli@chd.edu.cn

1 School of Environmental Science and Engineering, Chang'an University, 126 Yanta Road, Xi'an 710054, Shaanxi, China

2 Key Laboratory of Subsurface Hydrology and Ecological Effects in Arid Region (Chang'an University), Ministry of Education, 126 Yanta Road, Xi'an 710054, Shaanxi, China

3 Department of Physical and Environmental Sciences, University of Toronto at Scarborough (UTSC), 1265 Military Trail, Toronto, ON M1C 1A4, Canada

4 School of Engineering, RMIT University, Melbourne 3001, Australia with their painstaking efforts to understand the issues and develop effective solutions. Scientific research is the basis for sound planning and management of all resources (Li 2016) and, as such, is the key to the future health and prosperity of all humanity (Cheng 2016). Emerging young scientists have an especially important role to play. They have inherited environmental issues through no fault of their own but are able to bring fresh vitality and new perspectives that can drive research forward into uncharted territories. They represent the hope for the future and deserve support by every means possible.

This special issue of Environmental Science and Pollution Research was developed to recognize the increasingly valuable role that young scientists are making in solving the globe's serious environmental problems. It focuses on research papers solicited from outstanding young scholars in earth and environmental sciences under the age of 38 and showcases, in particular, the work of members of the International Association of Hydrogeologists Early Career Hydrogeologists' Network (IAH-ECHN). In total, 19 submissions were received and 7 were finally accepted for publication after peer review. They present new approaches to multidisciplinary research and provide fresh insights to solving current and emerging problems in the earth and environmental sciences.

\section{Contributors to this special issue}

This special issue includes six research papers and one review paper. The authors of the papers selected for publication are from Australia, China, Italy, Mexico, South Africa, and Thailand. All of these authors are working actively as hydrogeologists and environmental 
scientists in their respective countries and many are also collaborating internationally. Despite their youth, many have already received awards for their remarkable achievements. The lead authors of the selected papers are as follows:

Dr. Matthew Currell, born in 1982, obtained his Ph.D. in Environmental Geoscience from Monash University in 2010 and is currently working as a senior lecturer at the School of Engineering, RMIT University, Australia. $\mathrm{He}$ is an associate editor for Hydrogeology Journal. Matthew is a recognized expert in hydrogeology and groundwater geochemistry, and his research currently focuses on the use of environmental tracers in hydrogeology, the fate and transport of groundwater contaminants, and groundwater sustainability in arid and semi-arid regions. He has published over 20 papers in peer-reviewed journals and has participated in media interviews related to groundwater. His research paper titled "Controls on elevated fluoride and arsenic concentrations in groundwater from the Yuncheng Basin, China" has been recognized by the International Association of Geochemistry as one of the most influential papers (most cited over 5 years) published in the Applied Geochemistry.

Dr. Peiyue Li, born in 1984, is an associate professor in Hydrogeology and Environmental Science at Chang'an University, China. He obtained his Ph.D. degree in Groundwater Science and Engineering from Chang'an University in 2014. He is currently an associate editor for the journal of Exposure \& Health and is a guest editor for several well-recognized international journals published by Springer Nature, as well as a reviewer for more than 50 international journals. He was elected "an outstanding young scientific star" by the provincial government and has received ten provincial and national awards for recognizing his achievements in education and scientific research. He is now working in the fields of hydrogeochemistry, groundwater pollution, and groundwater quality with special emphasis on the interrelation between human activities and the groundwater environment. He has published over 80 research papers in peer-reviewed journals and his paper published in Nature entitled "Accelerate research on land creation" was selected as one of the best opinion pieces published in Nature in 2014.

Jie Chen, born in 1988, will receive her Ph.D. in Hydrology and Water Resources at Chang'an University, in 2017. Despite her youth, she has already published over ten research papers, several in highly regarded international journals. She has wide research interests that range from groundwater pollution and groundwater quality assessment to lake water quality. Her Ph.D. dissertation examines interactions between lake water and groundwater and their role in lake water quality variation.

Dr. Viviana Re, born in 1981 , is currently a postdoctoral research fellow at the University of Pavia, Italy. She obtained her Ph.D. degree in Analysis and Governance of Sustainable Development from the $\mathrm{Ca}^{\prime}$ Foscari University of Venice in 2011. She was awarded the 2015 Early Career Researchers Award for the promotion and recognition of research excellence within $\mathrm{Ca}^{\prime}$ Foscari University. Her research interests include environmental sciences with a focus on water sciences, hydrogeology, hydrogeochemistry, and isotope geochemistry and she supports science-based groundwater management. She was an associate editor of Acque Sotterranee - Italian Journal of Groundwater from 2012 to 2016, and the director of the IAH Early Career Hydrogeologists' Network from 2013 to 2016. She is now an associate editor for Hydrogeology Journal. She has published over ten papers in peer-reviewed journals and nearly 20 papers in conference proceedings.

Pablo Hernández Morales, born in 1977, is currently a $\mathrm{Ph} . \mathrm{D}$. student in marine and coastal sciences in the Autonomous University of Baja California Sur, Mexico. Before entering his Ph.D. program, he worked as an exploration geologist in the Mexican Geological Service from 2006 to 2010 and in Pitalla Mining Company from 2010 to 2013. His research interests include hydrogeochemistry and geothermal water development. He has published over ten papers in peerreviewed journals.

Brendon Ronald Jones, born in 1987, is a Ph.D. student majoring in Engineering Geology at University of Pretoria, South Africa, and expects to receive his degree during 2017. He is also currently a principal engineering geologist at GaGE Consulting which is based in Johannesburg. Brendon has a strong research and academic background, with his early research having been recognized by receiving the Haughton Award, as well as the SAIEG Student Award in 2010. He has published close to ten refereed journal articles and book chapters.

Dr. Tanapon Phenrat has been a lecturer at Naresuan University, Thailand, since 2010. She obtained her Ph.D. in Environmental Engineering and Science from Carnegie Mellon University, Pittsburgh, USA, in 2008 and worked as a post-doctoral research both at the same university and at the Colorado School of Mines before taking up the lectureship in Thailand. She has received several awards for her excellence in research. She has a wide range of research interests including nano-scale zero-valent iron, environmental system modeling, environmental forensics and site characterization, and 
quantitative risk assessment. She has published over ten papers in peer-reviewed journals.

\section{Manuscripts selected for the special issue}

With such an excellent array of young international authors, it is inevitable that the papers selected for publication feature cutting-edge research on a wide range of important issues. They range from the fundamental nature of groundwater flow, as investigated at the laboratory scale, to the risks and threats associated with groundwater pollution at the basin scale. The papers are briefly introduced below:

Rapid expansion of shale gas development as an unconventional source of energy has increased the need for various hydrochemical and geochemical studies, as there is concern that changes to the flow dynamics at a regional scale may cause severe groundwater quality deterioration. Investigations of methane origin and behavior were carried out in the Gippsland basin by Currell et al. (2017, this issue) using environmental isotopes $\delta 13 \mathrm{C}$ and $\delta 2 \mathrm{H}$ supported by broader hydrochemical analysis. This study will aid future shale gas development while enhancing groundwater quality protection.

China is undergoing rapid economic development that has led to severe environmental pollution including groundwater quality deterioration (Han et al. 2016). Two papers in this special issue are from Chinese scholars and relate to this concern. The research paper by Chen et al. (2017, this issue) examines factors controlling nitrogen contamination of groundwater in an agricultural region, Northwest China, using hydrochemical, hydrogeological, and isotopic techniques. Synthetic fertilizers and manure/ sewage were found to be the primary source of the pollution with either $\mathrm{NO}^{3-}$ or $\mathrm{NH}^{4+}$ predominant depending on local aquifer conditions. In the second Chinese paper, $\mathrm{Li}$ et al. (2017b, this issue) takes a broader perspective on groundwater quality research in China, reviewing recent progress and identifying ten fields of research that are urgently required. As indicated by the authors, groundwater quality research represents an unprecedented challenge in China (Li 2016), but also a great opportunity (Li et al. $2017 \mathrm{~b}$, this issue).

Soil salinization and groundwater nitrate pollution are commonly encountered in arid and semi-arid agricultural zones throughout the world ( $\mathrm{Li}$ et al. 2016a; Wu et al. 2014), and Re and Sacchi (2017, this issue) reveal the results of a hydrogeochemical and isotopic investigation of the salinity-pollution nexus in coastal aquifers of an arid Moroccan plain. Manure and septic effluent from urban areas and synthetic fertilizers from agricultural areas were identified as the two primary sources of pollution, and nitrate was found to play a key role in water-rock interaction processes.

Geothermal waters are widely abstracted for medical bathing, and their temperature and hydrochemical composition are key to their utility and effectiveness. Hernández-Morales and Wurl (2017, this issue) investigated geothermal spring waters in the Santiago watershed of Mexico using hydrochemistry including isotopes and showed that the temperature ranged from 70 to $115{ }^{\circ} \mathrm{C}$ for the deep thermal reservoir shows promise for geothermal energy development.

Variably saturated flow introduces an unwelcome level of complexity in hydrogeological studies but it can be an important phenomenon worthy of detailed research. Jones et al. (2017, this issue) conducted a series of centrifuge experiments, supported by numerical modeling, to fill knowledge gaps that exist between theory and practice. Their work on seepage flow and the relative importance of scale effect on parameters such as hydraulic gradient and hydraulic conductivity demonstrate the considerable benefits of geotechnical centrifuge studies and geotechnical centrifuge modeling, especially with regard to assessing hydrodynamic dispersion in unsaturated fracture zones. This study helps advance hydrogeological and environmental research in unsaturated zones.

Discharge of wastewater is one of the most common sources of water pollution in modern society ( $\mathrm{Li}$ et al. 2016b), posing significant risks to the environment and human health (Wu and Sun 2016). It contains a range of pollutants including trace metals, organics, and inorganics. Phenol is a toxic hydrocarbon that is common in industrial wastewater and may cause skin irritation and kidney inflammation, threatening human health. Effective degradation of phenol is a crucial component of industrial wastewater treatment. In the research paper by Phenrat et al. (2017, this issue), a two-phase phenoldegradation technique is introduced that uses vetiver plantlets. This technique can eliminate phenol over seven times more quickly than routine methods involving aerated microbial degradation. By providing a more efficient way of removing phenol in wastewater, the technique benefits both wastewater treatment and water quality protection.

\section{Final remarks}

Young scientists in earth and environmental sciences are playing an increasingly important role in scientific research 
and, with time, will have a major influence on policymaking in the fields of environmental management and protection. They represent our hope for the future. To help them develop more rapidly and fulfill their potential, governments, scientific societies, and experienced practitioners must support them to the fullest extent possible. Governments and funding agencies need to provide generous financial assistance. Veteran research scientists working closely with professional institutions need to provide guidance, mentorship, and, most of all, encouragement. This special issue of Environmental Science and Pollution Research is one small step in that direction and illustrates what can be achieved with the appropriate level of commitment from all concerned.

Acknowledgements The guest editors gratefully acknowledge the patience and generous help of the editorial staff of Environmental Science and Pollution Research in the production of this special issue. Particular thanks go to the editor in chief who strongly encouraged us to pursue this initiative, the associate editors for their efficient handling of the manuscripts, and the assistant editor who regularly kept us up to date with progress. Of course, none of this would have been possible without the hard work and enthusiasm of the contributors, many of whom were writing in English as their second or third language. Whether your manuscript was published or not, your efforts are greatly appreciated. Finally, special thanks go to the peer reviewers, many of whom remain anonymous. The comments and suggestions of reviewers have proved invaluable for improving the quality of the manuscripts but have also helped the authors with their research. Young scholars in the earth and environmental sciences thank you all.

\section{References}

Chen J, Qian H, Wu H (2017) Nitrogen contamination in groundwater in an agricultural region along the New Silk Road, Northwest China: distribution and factors controlling its fate. Environ Sci Pollut Res. doi: $10.1007 / \mathrm{s} 11356-017-8881-0$

Cheng H (2016) The rising young scientist stars in China. Protein Cell 7(12):850-853. doi:10.1007/s13238-016-0347-5

Currell M, Banfield D, Cartwright I, Cendón DI (2017) Geochemical indicators of the origins and evolution of methane in groundwater: Gippsland Basin, Australia. Environ Sci Pollut Res. doi:10.1007/ s11356-016-7290-0

Currell M, Han D (2017) The global drain: why China's water pollution problems should matter to the rest of the world. Environ Sci Policy Sustain Dev 59(1):16-29. doi:10.1080/00139157.2017.1252605

Han D, Currell M, Cao G (2016) Deep challenges for China's war on water pollution. Environ Pollut 218:1222-1233. doi:10.1016/j. envpol.2016.08.078

Hernández-Morales P, Wurl J (2017) Hydrogeochemical characterization of the thermal springs in northeastern of Los Cabos Block, Baja California Sur, México. Environ Sci Pollut Res. doi:10.1007/ s11356-016-8087-x

Howard KWF, Howard KK (2016) The new "Silk Road Economic Belt" as a threat to the sustainable management of Central Asia's transboundary water resources. Environ Earth Sci 75:976. doi:10. 1007/s12665-016-5752-9

Jones BR, Brouwers LB, Van Tonder WD, Dippenaar MA (2017) Assessing geotechnical centrifuge modelling in addressing variably saturated flow in soil and fractured rock. Environ Sci Pollut Res. doi: 10.1007/s11356-016-8333-2
Li P (2016) Groundwater quality in Western China: challenges and paths forward for groundwater quality research in Western China. Expo Health 8(3):305-310. doi:10.1007/s12403-016-0210-1

Li P, Qian H, Wu J (2014) Accelerate research on land creation. Nature 510(7503):29-31. doi:10.1038/510029a

Li P, Qian H, Howard KWF, Wu J (2015) Building a new and sustainable "Silk Road economic belt". Environ Earth Sci 74(10):7267-7270. doi:10.1007/s12665-015-4739-2

Li P, Wu J, Qian H (2016a) Regulation of secondary soil salinization in semi-arid regions: a simulation research in the Nanshantaizi area along the Silk Road, Northwest China. Environ Earth Sci 75(8): 698. doi:10.1007/s12665-016-5381-3

Li P, Wu J, Qian H, Zhang Y, Yang N, Jing L, Yu P (2016b) Hydrogeochemical characterization of groundwater in and around a wastewater irrigated forest in the southeastern edge of the Tengger Desert, Northwest China. Expo Health 8(3):331-348. doi:10.1007/ s12403-016-0193-y

Li P, Qian H, Zhou W (2017a) Finding harmony between the environment and humanity: an introduction to the thematic issue of the Silk Road. Environ Earth Sci 76(3):105. doi:10.1007/s12665-017-6428-9

Li P, Tian R, Xue C, Wu J (2017b) Progress, opportunities and key fields for groundwater quality research under the impacts of human activities in China with a special focus on western China. Environ Sci Pollut Res. doi:10.1007/s11356-017-8753-7

Phenrat T, Teeratitayangkul P, Prasertsung I, Parichatprecha R, Jitsangiam P, Chomchalow N, Wichai S (2017) Vetiver plantlets in aerated system degrade phenol in illegally dumped industrial wastewater by phytochemical and rhizomicrobial degradation. Environ Sci Pollut Res. doi:10.1007/s11356-016-7707-9

Re V, Sacchi E (2017) Tackling the salinity-pollution nexus in coastal aquifers from arid regions using nitrate and boron isotopes. Environ Sci Pollut Res. doi:10.1007/s11356-017-8384-z

Wu J, Li P, Qian H, Fang Y (2014) Assessment of soil salinization based on a low-cost method and its influencing factors in a semi-arid agricultural area, Northwest China. Environ Earth Sci 71(8):34653475. doi:10.1007/s12665-013-2736-X

Wu J, Sun Z (2016) Evaluation of shallow groundwater contamination and associated human health risk in an alluvial plain impacted by agricultural and industrial activities, mid-west China. Expo Health 8(3):311-329. doi:10.1007/s12403-015-0170-x

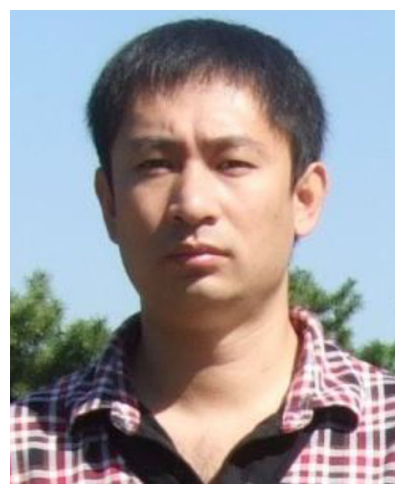

Dr. Peiyue $\mathbf{L i}$ is an associate professor of hydrogeology and environmental science at Chang'an University, China. He obtained his bachelor's, master's, and doctoral degrees from Chang'an University in 2008, 2011, and 2014, respectively. He has been a member of the International Association of Hydrogeologists (IAH), International Mine Water Association (IMWA), and National Ground Water Association (NGWA) of the USA since 2014 and serves as an Associate Editor for Exposure \& Health since 2016. He has wide experience in groundwater environment assessment, hydrogeochemistry, and groundwater modeling. He has published over 80 articles in refereed journals on topics that range from groundwater quality assessment and groundwater hydrochemistry to groundwater pumping tests and in situ tracer tests. 


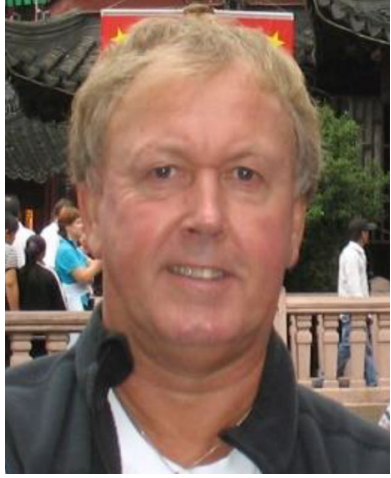

Dr. Ken W F Howard received his $\mathrm{Ph} . \mathrm{D}$. from the University of Birmingham, UK, in 1979 and is currently a professor of hydrogeology at the University of Toronto, Canada. He is a hydrogeologist, certified by the American Institute of Hydrology, chartered by the British Geological Society, and registered as a professional geoscientist with the Association of Professional Geoscientists of Ontario. He has wide experience in all aspects of groundwater resource evaluation, management, and protection. He was the President of the International Association of Hydrogeologists (IAH) from 2012 to 2016 and currently serves as the past president. He has published well over 120 articles in refereed journals on topics that range from numerical flow modeling and contaminant migration to environmental isotopes and borehole geophysics. He has also authored or co-authored six books.

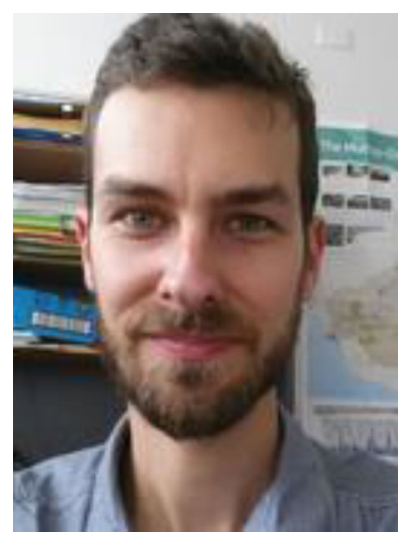

Dr. Matthew Currell is a senior lecturer at RMIT University, Australia. He obtained his Ph.D. degree in Environmental Geoscience from Monash University in 2010. After his doctoral graduation, he worked as an environmental consultant at Sinclair Knight Merz, Australia, before joining the RMIT University as a lecturer in 2011 . He has been an Associate Editor for Hydrogeology Journal since 2014. He is also a committee member of the Victorian Branch of the International Association of Hydrogeologists (IAH) and has wide expertise in hydrogeology and groundwater geochemistry. His research interests currently include environmental tracers in hydrogeology, the transport and fate of groundwater contaminants, and groundwater sustainability in arid and semi-arid regions. He has published over 20 papers in peer-reviewed journals on topics ranging from geochemical origins of pollutants to groundwater management. 